\title{
SUSTENTABILIDADE DE EMPRESAS DE BASE FLORESTAL: O PAPEL DOS PROJETOS SOCIAIS NA INCLUSÃO DAS COMUNIDADES LOCAIS ${ }^{1}$
}

\author{
Antônio do Nascimento Gomes ${ }^{2}$, Agostinho Lopes de Souza ${ }^{3}$, France Maria Gontijo Coelho ${ }^{4}$ e Márcio \\ Lopes da Silva ${ }^{3}$
}

\begin{abstract}
RESUMO - A partir de estudo de casos, buscou-se interpretar as ações sociais de empresas produtoras de celulose de fibra curta de mercado, localizadas no Estado do Espírito Santo e extremo sul da Bahia, com vistas a verificar a sua consistência com a estratégia de sustentabilidade empresarial. Buscou-se, também, caracterizar seus programas de ações sociais e sua abrangência, ao analisar o conteúdo dos instrumentos de divulgação das ações sociais das empresas e identificar a concepção que tem orientado essas ações sociais e sua relação com as comunidades influenciadas pelas suas áreas de produção de eucalipto.
\end{abstract}

Palavras-chave: Sustentabilidade, responsabilidade social e comunidades locais.

\section{SUSTAINABILITY OF FOREST BASED ENTERPRISES: THE ROLE OF SOCIAL PROJECTS IN THE INCLUSION OF THE LOCAL COMMUNITIES}

\begin{abstract}
The objective of this study was to interpret, based on case studies, the social actions of short fiber market pulp companies, located in the States of Espírito Santo and extreme South of Bahia, in order to verify their consistency with the strategy of business sustainability; to characterize their programs of social actions and their scope, by analyzing the content of the communication tools of these companies' social actions, and to identify the conception that has guided their social actions and the relationship with the communities influenced by their areas of eucalyptus production .
\end{abstract}

Keywords: Sustainability, social responsibility and local communities.

\section{INTRODUÇÃO}

Há um reconhecimento crescente, em níveis doméstico e internacional, de que o impacto da atividade econômica sobre as comunidades pobres tem importante resultado social e ambiental. Nesse sentido, há percepção de que as empresas têm papel essencial a cumprir, juntamente com os governos e a sociedade civil, na solução das imensas desigualdades sociais. Os movimentos de responsabilidade social são respostas a tais desigualdades.

Apesar de inexistir um conceito único para o termo responsabilidade social, três aspectos podem ser considerados como a essência de sua definição: a ampliação do alcance da responsabilidade da empresa,

\footnotetext{
${ }^{1}$ Recebido em 26.06.05 e aceito para publicação em 13.09.2006.

${ }^{2}$ ARACRUZ CELULOSE. E-mail: <anngomes@aracruz.com.br>.

${ }^{3}$ Departamento de Engenharia Florestal da Universidade Federal de Viçosa, 36571- 000 Viçosa-MG. E-mail: <alsouza@ ufv.br> e e <marlosil@ufv.br>.

${ }^{4}$ Departamento de Economia Rural da Universidade Federal de Viçosa, 36571- 000 Viçosa-MG. E-mail: <fmcoelho@ufv.br>.
} 
que não mais se limita aos interesses dos acionistas; a mudança na natureza das responsabilidades, que ultrapassa o âmbito legal e envolve as obrigações morais ditadas pela ética; e a adequação às demandas sociais mais atuantes e exigentes (DUARTE e DIAS, 1986).

Pesquisas recentes apontaram que, dentro desse conceito, a responsabilidade social vem-se tornando cada vez mais um fator decisivo para o crescimento e sobrevivência das empresas e evidenciando que o papel destas no desenvolvimento local deve ser debatido a partir de uma concepção mais sistêmica, superando a idéia tradicional de que o papel das empresas se resume à geração de riquezas e de empregos e ao pagamento de impostos.

Algumas, pela característica de seus produtos ou serviços, alteram profundamente o ambiente e a vida das comunidades onde estão inseridas, a exemplo das empresas de produção de celulose, cuja matéria-prima é oriunda de extensas plantações florestais.

Essas empresas estão sujeitas a maiores e crescentes pressões em termos de exigências ambientais e sociais, sendo necessária uma responsabilidade maior sobre os impactos locais de suas ações. Assim, um de seus grandes desafios é atingir o equilíbrio entre as diferentes demandas, muitas vezes conflitantes, de todas as partes interessadas e relacionadas com suas atividades industriais e florestais.

\subsection{Relação empresa e comunidade}

As atividades de responsabilidade social afetam o estoque de capital reputacional e, conseqüentemente, o valor dos ativos intangíveis da organização (FOMBRUN et al., 2001). Dessa forma, podem preservar ou agregar valor às empresas sob dois aspectos: criando vantagem competitiva, por meio do aprimoramento da capacidade da empresa em atrair e manter recursos, e minimizando riscos potenciais. Assim, o estabelecimento de relações positivas com a comunidade local deve ser considerado, pelas empresas, como um ativo na forma de acumulação de capital social, que deve ser capitalizado para garantir a licença para operar. As empresas devem usar todos os seus recursos - contratação de pessoal e de serviços, investimentos financeiros e outros - para afetar as comunidades de forma a fortalecer a sua estrutura econômica e social e criar um ambiente mais estável, no qual realiza os seus negócios (MONAGHAN et al., 2003). Entretanto, além dos benefícios, existem custos e riscos no relacionamento com as comunidades. Mas, em geral, quanto maior o nível de engajamento, maior o potencial de resultados positivos, assim como maior investimento de tempo e recursos requeridos.

As visões sobre a responsabilidade social das empresas podem ser representadas por um modelo de duas dimensões: a dimensão da responsabilidade social; e a dimensão dos resultados derivados do compromisso social dos negócios (custos ou benefícios) (QUAZI e O'BRIEN, 2000). Baseando-se nessas dimensões, os autores descreveram um modelo de responsabilidade social corporativa que pode ser representado graficamente através de dois eixos (Figura 1), que define em seus quadrantes as seguintes visões:

- Visão clássica: corresponde à visão primária da responsabilidade social. As empresas consideram que as ações de responsabilidade social não geram valor para a empresa e, portanto, não devem ser desenvolvidas.

- Visão socioeconômica: considera que a função-objetivo da empresa é a maximização do valor para o acionista, mas que as ações de responsabilidade social podem ajudar nessa geração de valor. Nesse contexto, as ações de responsabilidade social podemse justificar, inclusive quando a direção mantém uma visão reduzida a respeito.

- Visão filantrópica: defende as ações de responsabilidade social, mesmo que não tragam retornos para a empresa.

- Visão moderna: trata-se de uma perspectiva segundo a qual a empresa mantém uma relação ampla com a sociedade e obtém benefícios líquidos de curto e longo prazos, derivados da responsabilidade social corporativa.

Baseando-se na teoria tradicional da firma, as ações de responsabilidade social devem ser vistas como uma forma de investimento que a corporação estaria fazendo no sentido de buscar a maximização do valor. McWilliams e Siegel (2001) afirmaram que, dessa maneira, existiria um nível de investimento em responsabilidade social corporativa que maximizaria os lucros, ao mesmo tempo que estaria satisfazendo as demandas por atividades de responsabilidade social dos múltiplos stakeholders (uma pessoa ou um grupo de pessoas que afeta e é afetado pelas atividades da empresa). 


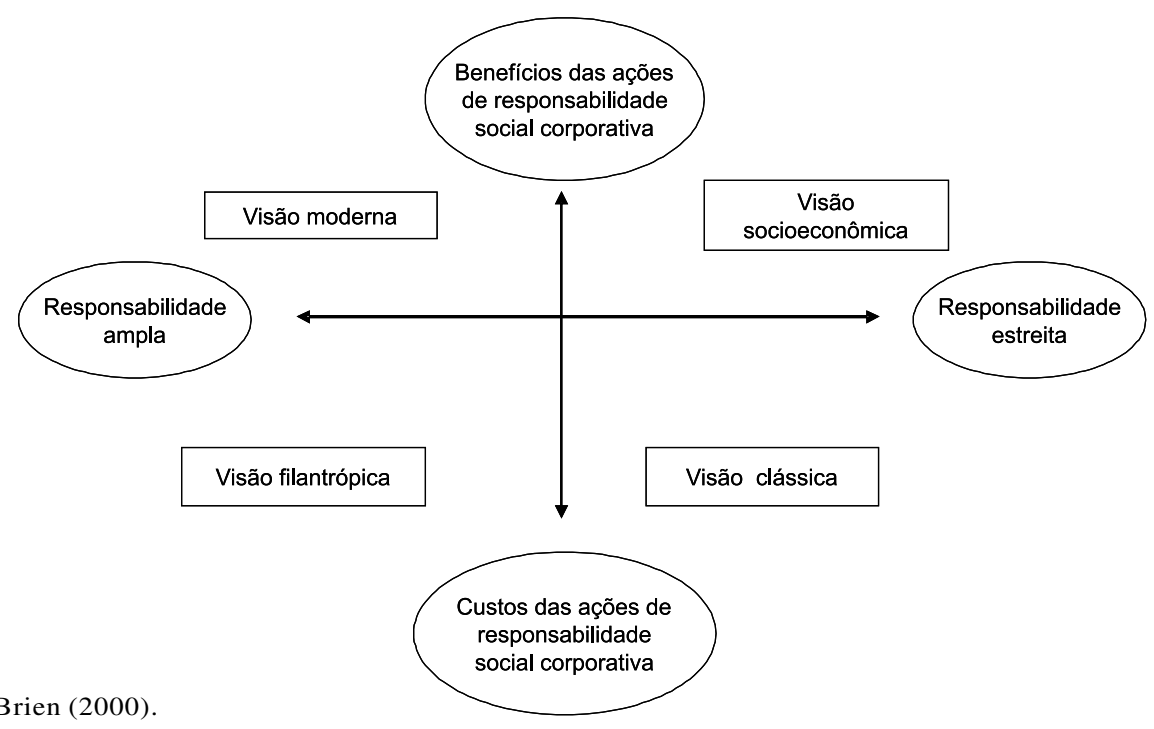

Fonte: Quazi e O’Brien (2000).

Figura 1 - Modelo bidimensional de responsabilidade social corporativa (RSC).

Figure 1 -Bidimensional model of corporate social responsibility (CSR).

Nesse sentido, GIFE $(2004)^{5}$ definiu o investimento social privado como o uso planejado, monitorado e voluntário de recursos privados em ações sociais e projetos de interesse público realizadas por empresas, fundações e institutos de origem empresarial ou instituídos por famílias ou indivíduos.

O envolvimento da comunidade no desenvolvimento da ação, a preocupação com os resultados obtidos e as transformações geradas, além do planejamento, do monitoramento e da avaliação dos projetos, são os elementos fundamentais na diferenciação entre o conceito de investimento social privado e as ações assistencialistas.

Outros aspectos importantes das abordagens mais avançadas sobre a concepção e implantação de projetos sociais por parte de empresas (TEODÓSIO, 2000) são:

- Retorno do projeto: o pressuposto é de que não só a comunidade pode ter grandes ganhos com o suporte empresarial, mas também que as organizações podemse tornar mais produtivas e competitivas à medida que desenvolvem ações sociais.

- Relação empresa - comunidade: por meio de parcerias, onde os projetos devem ser concebidos e desenvolvidos em conjunto com membros representativos das comunidades assistidas, procurando partilhar ações, custos e soluções a serem implementadas.

- Sustentabilidade do projeto: os projetos não podem caracterizar-se pela extrema dependência de uma única fonte de financiamento externa, devendo caminhar para a auto-sustentação no médio e longoprazos. Um problema social relevante em determinado momento pode não o ser no futuro. No entanto, se o projeto social é extremamente dependente da empresa, ela não pode modificar sua pasta de investimentos sociais sob pena de comprometer os projetos que já estão em execução.

Além desses aspectos, as empresas devem investir em projetos que promovam o desenvolvimento socioeconômico das comunidades onde operam e que tenham a participação de representantes da sociedade civil, do governo e da comunidade em questão; envolvam planejamento participativo; sejam partes de um programa estratégico, baseado nas necessidades e nos impactos do desenvolvimento; e priorizem grupos vulneráveis ou marginalizados (como os sem terra, analfabetos, comunidades indígenas, deficientes físicos e desempregados) (ETHOS, 2004).

\footnotetext{
${ }^{5}$ O GIFE - Grupo de Institutos, Fundações e Empresas é uma associação brasileira que reúne organizações de origem privada que financiam ou executam projetos sociais, ambientais e culturais de interesse público.
} 
Existem três estágios de envolvimento com a comunidade que podem ser vistos como um continuum, variando de baixo até alto valor estratégico, e de uma baixa até alta integração ao longo de toda a empresa: Consciente, Experiente e Integração (ROCHLIN e BOGUSLAW, 2001).

O estágio "Consciente" é o mais comum do envolvimento. As empresas nesse estágio se envolvem, inicialmente, através de doações e de programas de voluntariado por parte de seus empregados. Os tradicionais departamentos de relações comunitárias ou fundações dirigem o envolvimento corporativo, e suas iniciativas permanecem isoladas do negócio, sendo que qualquer tipo de resultado raramente é medido.

As empresas no estágio "Experiente" começam a implementar uma ação mais estratégica. Tipicamente dirigidas pelos departamentos de relações comunitárias, essas empresas se engajam na chamada "filantropia estratégica" ou "investimento na comunidade". Nesse estágio, os benefícios corporativos serão, frequientemente, intangíveis e podem incluir a melhoria da reputação, imagem, aumento da satisfação dos empregados, desenvolvimento de novas relações com stakeholders-chave e preservação da "licença para operar".

Por fim, no estágio de "Integração" as empresas vêem o envolvimento com as comunidades como uma oportunidade de mercado e integram e alinham suas funções de envolvimento com a comunidade com suas linhas de negócio, quebrando as barreiras, reais e percebidas, entre elas e as comunidades. As empresas nesse estágio elaboram estratégias com a participação e recursos de todas as atividades do negócio e desenvolvem ações que aumentam os recursos econômicos e sociais das comunidades onde atuam, por meio de suas atividades regulares e pelo investimento dos recursos fins da empresa, em oposição à filantropia.

Tipicamente, as empresas podem ser enquadradas em um desses três estágios de envolvimento, progredindo em um processo evolutivo em direção à integração. Esses estágios identificam onde a empresa se encontra no seu envolvimento e fornecem uma visão de como obter maiores retornos a partir de investimentos corporativos no desenvolvimento da comunidade.

Ressalta-se, contudo, que o ambiente social, político, econômico e legal onde a empresa atua é dinâmico e sistêmico, e conseqüientemente as necessidades e padrões de comportamento desejáveis pela sociedade também o são. A principal implicação desse pressuposto é de que a responsabilidade social é um processo contínuo de monitoramento do ambiente e das relações e não uma missão fixa em relação a grupos específicos com predeterminada prioridade que permanece estática (BORGER, 2001).

Nesse contexto, este estudo teve como objetivo geral analisar as ações sociais desenvolvidas nas comunidades pelas empresas produtoras de celulose de fibra curta de mercado com plantios florestais instalados no norte do Espírito Santo e extremo sul da Bahia, com vistas a identificar as motivações, estratégias e modelos adotados nas ações sociais, bem como verificar a sua consistência com o modelo de gerenciamento de sustentabilidade empresarial.

\section{METODOLOGIA}

\subsection{Caracterização da pesquisa}

Considerando que este estudo é de natureza qualitativa por se ater a responder questões particulares e trabalhar com um nível de realidade que não pode ser totalmente quantificado, ou seja, com motivos, crenças, valores, comportamentos e percepções individuais (DESLANDES, 1994), a forma de abordagem é empírica, diferindo do método quantitativo, por não empregar um instrumental estatístico como base para analisar determinado problema. Trata-se de uma forma adequada para entender a natureza de um fenômeno, uma vez que a quantificação, em certos casos, apresenta limitações ao tentar explicitar problemas complexos (RICHARDSON et al., 1999).

A pesquisa foi desenvolvida pelo método de Estudos de Casos Múltiplos que é caracterizado como aquele que ocorre quando os investigadores estudam dois ou mais assuntos, ambientes, ou bases de dados e que podem assumir uma grande variedade de formas (BOGDAN e BIKLEN, 1994).

Nesse tipo de pesquisa é necessário ter clareza das implicações e do que significa dados de natureza qualitativa. Essa clareza conceitual é fundamental para a validação das informações utilizadas na análise, pois não há como assumir uma postura de neutralidade absoluta, uma vez que um dos pesquisadores é profissional contratado de uma das empresas estudadas, 
exercendo uma função gerencial na qual vivencia e administra diversas questões relativas ao problema em análise.

Daí a necessidade de se assumir que a análise que aqui se faz é relativamente objetivada a partir dessa perspectiva. Em realidade, sabe-se que isso acontece em qualquer pesquisa, pois, mesmo quando os dados se apresentam na linguagem numérica ou em medidas, eles representam qualidades quantificadas. Contudo, numa pesquisa na qual os dados são discursivos e há uma posição de engajamento do pesquisador no espaço social do problema, exige-se que suas interpretações busquem um distanciamento constante, a fim de permitir não perder a possibilidade da dúvida.

\subsection{Abrangência do estudo}

Para este estudo foram avaliados os programas e as ações de envolvimento das empresas com as comunidades enfocando os projetos sociais das empresas produtoras de celulose de fibra curta de mercado instaladas no norte do Espírito Santo e extremo sul da Bahia.

\subsection{Descrição da área}

A estrutura fundiária da região apresenta elevados níveis de concentração (MOTA et al., 2003). Essa concentração de terras é originada na própria formação do estado brasileiro e no início do seu processo de colonização. Além desses fatores históricos gerais, a região de estudo foi submetida a um isolamento físico durante os processos iniciais de colonização e ocupação, que perdurou por muito tempo. Sua ocupação está associada aos ciclos econômicos mais recentes, estando diretamente relacionada às atividades de extração de madeira da floresta nativa e, posteriormente, a algumas atividades tradicionais como pecuária extensiva, pesca artesanal e agricultura de subsistência.

Ao longo das últimas décadas - 1960, 1970, 1980 e 1990 - essa configuração vem se modificando, devido aos significativos investimentos estatais e privados, o que vem propiciando o crescimento de novos setores da economia. Entre esses setores, destaca-se a silvicultura, por meio do plantio de eucalipto, especialmente voltados para a produção de celulose, utilizando-se de terras que vinham sendo trabalhadas pela pecuária extensiva, plantações de mamão, agricultura de subsistência, ou incorporando novas áreas improdutivas.
A introdução e expansão dos maciços florestais vêm sendo acompanhadas de significativas transformações na estrutura social e econômica dos municípios na área de influência, sendo que os maiores impactos se refletem, principalmente, nas comunidades rurais situadas nos pequenos povoados e seu entorno.

Esses efeitos têm sido potencializados por condições estruturais precárias, como baixa escolaridade, falta de incentivo para o desenvolvimento de novas atividades, inexistência ou precariedade dos serviços básicos - esgotamento sanitário, coleta de lixo, água tratada, energia elétrica, escolas de ciclos mais avançados, vias de acesso e transporte regular.

Na região está instalado um importante complexo integrado e verticalizado de naturezas florestal e industrial para a produção de celulose de fibra curta, composto pelos empreendimentos da Aracruz Celulose e da Bahia Sul Celulose, cujas unidades fabris se localizam, respectivamente, nos Municípios de Aracruz, Estado do Espírito Santo, e Mucuri, na Bahia. O perfil econômico desse complexo é caracterizado por ser um ramo bastante intensivo em capital, voltado para o mercado externo.

A matéria-prima utilizada por essas empresas é o eucalipto, cujos plantios estão distribuídos em diversos municípios da região estudada, totalizando aproximadamente $320 \mathrm{mil}$ hectares. Além dos plantios próprios, as empresas mantêm programas de fomento para produtores da região, totalizando aproximadamente 90 mil hectares.

Esta latifundização promovida pelas empresas tem sido o alvo das principais controvérsias relacionadas às atividades florestais. Os grupos que lutam pela reforma agrária, representados principalmente pelo Movimento dos Trabalhadores Rurais sem Terra (MST), Movimento de Libertação da Terra (MLT) e Movimento dos Pequenos Agricultores (MPA), defendem um modelo alternativo de ocupação, por meio de pequenas propriedades voltadas prioritariamente para a produção de alimentos para consumo próprio e comercialização no mercado interno. Defendem também que esse é o modelo que gera maior número de empregos, atribuindo à expansão dos plantios de eucalipto o aumento no preço das terras, o êxodo rural e as consequiências ambientais adversas da monocultura em grande escala.

A região é também o palco de atuação de outras organizações não-governamentais que atuam como

R. Árvore, Viçosa-MG, v.30, n.6, p.951-960, 2006 
mediadoras de outros movimentos sociais, como os quilombolas, indígenas e agricultores familiares, destacando-se a Federação de Órgãos para Assistência Social e Educacional (FASE), regional Espírito Santo, que se propõem discutir propostas alternativas de modelo de geração e divisão de riquezas e de ocupação do território e coordena a Rede Alerta Contra o Deserto Verde (FASE, 2005).

\subsection{Coleta, análise e tratamento de dados}

Considerando os objetivos deste estudo, os dados foram obtidos por meio de pesquisa documental, utilizando-se técnicas de análise de conteúdo (KRIPPENDORFF, 1980), que é uma técnica de pesquisa que permite fazer inferências replicáveis e válidas dos dados, a partir do seu contexto.

Os documentos analisados foram os relatórios anuais, social e ambiental e o balanço social das empresas referentes ao ano de 2003.

O acesso aos documentos foi obtido nas páginas eletrônicas (internet) das empresas. Além disso, foram utilizadas entrevistas de natureza semi-estruturada, realizadas com profissionais ligados diretamente à gestão dos projetos sociais das empresas pesquisadas. A flexibilidade desse dispositivo permite recolher a interpretação dos interlocutores, respeitando seus quadros de referência. A finalidade das entrevistas foi a obtenção de informações mais detalhadas e complementares às divulgadas nos documentos analisados e seguiu o seguinte roteiro: Como surgiu o projeto (histórico), Público-alvo, O que se pretende com o projeto, Como o projeto é conduzido ou gerenciado, Como ou o que é avaliado e Formas de divulgação.

A análise de dados seguiu a orientação de técnicas de análise de conteúdo, a partir dos referenciais teóricos de Bardin (1979), utilizando-se a análise temática, organizada em três etapas: 1) a pré-análise, 2) a exploração do material, e 3 ) o tratamento dos resultados obtidos, ou seja, a inferência e a interpretação.

Os resultados são apresentados de maneira descritiva e analítica, conforme o assunto focalizado, utilizando-se a quantificação apenas nos casos relevantes para a compreensão do fato.

Adotou-se, como estratégia de análise e interpretação, o padrão de confrontação, no qual o referencial teórico construído a partir da pesquisa bibliográfica foi usado como padrão de comparação para interpretar os dados e extrair inferências de acordo com os construtos e indicadores desejados.

Nas pesquisas qualitativas, no momento da análise o pesquisador já deve ter uma idéia das possíveis direções teóricas do estudo e parte, então, para trabalhar o material acumulado e destacar os principais achados da pesquisa (LÜDKE e ANDRÉ, 1986).

O modelo de Quazi e O’brien (2000) foi utilizado para mapear as visões que levaram à motivação para ações de responsabilidade social por parte das empresas analisadas. Enquanto, a partir das evidências levantadas foi feito o enquadramento das empresas em relação ao estágio de envolvimento com a comunidade (ROCHLIN e BOGUSLAW, 2001) e identificada a principal motivação para as ações de envolvimento com as comunidades de acordo com o modelo de Fombrun et al. (2001).

\section{RESULTADOS E DISCUSSÃO}

Nos documentos analisados são relatados 27 projetos, que são apresentados pelas empresas como sendo seus esforços de atuação social nas comunidades onde operam.

Vários projetos foram inicialmente criados para utilizar as linhas de financiamento oferecidas pelo BNDES e continuam em funcionamento, com o apoio das empresas, mesmo após o término das linhas de crédito externo. Entretanto, por meio das entrevistas constatouse que alguns projetos relacionados à construção de infra-estrutura básica, como escolas e postos de saúdes, executados no passado em função dessa atuação do banco, atualmente se encontram sucateados e abandonados pelo setor público, evidenciando a ineficácia do processo de seleção e definição dos referidos projetos. Isso decorreu da inexistência de um adequado diagnóstico local e por desconsiderar as necessidades e as expectativas das comunidades, que em última instância detém conhecimento de suas necessidades e, sobretudo, de suas prioridades.

Embora não esteja divulgado em seus balanços sociais, foi relatado nas entrevistas que as empresas atendem a inúmeras solicitações de natureza bastante diversificada, oriundas principalmente de setores da sociedade civil organizada, como: associações comunitárias e representações de classe, clubes de serviços e organizações não-governamentais, prefeituras 
municipais, câmaras de vereadores e escolas. Essas solicitações vão desde madeira de eucalipto, folhas de celulose e papel, empréstimo de máquinas, equipamentos e mão-de-obra para melhoria de estradas, patrocínio financeiro para festas e outros eventos comemorativos até projetos pontuais, geralmente de caráter assistencialista, destinados a mitigar diferentes mazelas sociais.

Os projetos analisados foram agrupados de acordo com o foco de atuação, conforme a seguinte classificação:

a) Área de educação, cultura, treinamento e capacitação profissional: Formar; Meninos da Terra; Estudante do Futuro; Universidade para Todos; Araçá; Pólo de Educação Ambiental; Formação Profissional; Formando o Cidadão; Cidadão Educar; Crescer; Associação Comunitária Golfinho; Sementeira; Clube da Semente; Ler é Preciso; e Bolsa de Estudo.

b) Área de saúde: Reabilitar Semana da Saúde Esporte com Saúde e Associação Comunitária Golfinho.

c) Área de geração de renda: Comunidades Negras, Comunidades Pesqueiras, Viveiros Comunitários, Agricultura Familiar, Centro Cultural Golfinho e Fomento Florestal.

d) Outros projetos: Bons Vizinhos, Comunidades Indígenas e Formação de Gestores de Entidades Sociais.

Dentre todos os projetos, o de fomento florestal destacou-se na atuação das empresas por ser planejado, estruturado e alinhado com a função-objetivo de maximização de valor das empresas, sendo uma importante fonte alternativa de abastecimento de madeira e geração de valor para a sociedade. Além de obter a matéria-prima a custos compatíveis, as empresas agregam valor ao negócio pela não-imobilização de capital na aquisição de terras e pela melhoria em suas imagens, em função das parcerias formadas e pela inclusão de pequenos produtores rurais na cadeia produtiva. Por sua vez, para o governo e a sociedade tais programas agregam valor por meio da geração de renda, impostos, empregos e favorecendo a fixação da mão-de-obra na região, além de contribuir para diminuir a pressão antrópica sobre as florestas nativas e não aumentar a concentração fundiária.

Os projetos em execução tiveram diversas origens e evidenciam um processo de surgimento majoritariamente "de fora para dentro", sendo: demandas e propostas apresentadas por instituições e entidades interessadas (35\%); atendimento a termos de ajustamento de conduta e condicionantes de licenças ambientais (7\%); atendimento de exigências contratuais de financiamentos do BNDES (10\%); demandas operacionais $(21 \%)$; demandas de programas de voluntariado (3\%); e iniciativas das empresas (24\%).

Os focos principais de atuação são a educação (52\%), geração de renda (24\%) e saúde (14\%). Entretanto, evidencia-se, em relação às áreas de atuação dos projetos, uma diferença entre as empresas estudadas, pois os projetos voltados para a educação e saúde correspondem a $77 \%$ dos projetos relatados de uma empresa e $56 \%$ de outra.

Considerando que as comunidades rurais situadas nos pequenos povoados circundados pelos plantios de eucalipto são as mais afetadas pela atuação das empresas, devendo, portanto, ser consideradas como stakeholders prioritários, observa-se um descompasso na atuação das empresas, pois apenas $14 \%$ dos projetos analisados têm atuação voltada para esse segmento (Viveiros comunitários, Agricultura familiar, Comunidades negras e Projeto bons vizinhos).

Para a condução dos projetos, de acordo com os documentos e entrevistas as empresas adotam uma opção externa, por meio de parcerias com outras instituições, aportando recursos financeiros e participando, com maior ou menor grau de envolvimento do planejamento e acompanhamento, mas não operando diretamente as ações. Assim, os projetos são executados majoritariamente por instituições parceiras, como secretarias de governos, sindicatos de trabalhadores, entidades empresariais, igrejas, organizações comunitárias e organizações não-governamentais.

Constata-se ainda que não há parcerias na atuação dos projetos avaliados entre as empresas estudadas. Considerando-se que essa parceria poderia reduzir a fragmentação do atendimento e ampliar, em muito, o alcance das atividades empresariais, observa-se, aí, um grande espaço para racionalização e otimização do uso dos recursos.

De acordo com os relatórios analisados, em 2003 o valor agregado dos investimentos sociais das duas empresas foi de $\mathrm{R} \$ 11,9$ milhões, o que representa $0,21 \%$ da receita líquida total dessas empresas. Esse valor corresponde, de acordo com os entrevistados, aos gastos

R. Árvore, Viçosa-MG, v.30, n.6, p.951-960, 2006 
com os projetos sociais voltados para as comunidades, bem como outras ações voltadas para o público interno, e parte dos apoios e doações diversas e não inclui os valores relativos ao fomento florestal, que somente em uma das empresas totalizou $\mathrm{R} \$ 70$ milhões (1,3\%), considerando-se o programa de plantio e a compra de madeira.

Constatou-se que, embora avaliem se os projetos alcançaram as metas previstas, as empresas estudadas não possuem uma metodologia estruturada para avaliação dos impactos dos projetos sociais, bem como não têm um sistema que contabilize os possíveis retornos das atividades sociais desenvolvidas e a geração de valor para a empresa. Entretanto, ambas reportam ganhos de imagem corporativa com essas ações.

Os impactos dos projetos, em geral, são percebidos nos campos das gratificações emocionais e da melhoria nas condições de vida das comunidades. No entanto, essas percepções são subjetivas, pois os projetos são avaliados de forma inconsistente, sem definição de indicadores e sem participação do público beneficiado. Isso pode ser em razão de os projetos não se iniciarem a partir de um diagnóstico para o estabelecimento de proposições e expectativas, não havendo uma caracterização sociológica mais precisa dos grupos sociais envolvidos. Além disso, ficou evidenciado nas entrevistas que não se recorre a avaliações externas por meio de instituições ou de pessoas especializadas, à exceção dos projetos Sementeira e Clube das Sementes. Isso seria importante para ampliar o conhecimento sobre o que é feito, promover o intercâmbio de experiências e racionalizar o uso dos recursos.

De acordo com as entrevistas, a divulgação dos projetos se faz por meio de mala direta, internet, intranets, jornais e revistas corporativos. Contudo, os entrevistados afirmaram que a divulgação dos projetos é um ponto crítico para as empresas, pois, de modo geral, as comunidades vizinhas não conhecem os seus projetos.

A análise do balanço social, relatório social e ambiental e dos relatórios anuais, demonstra que o principal discurso identificado nos textos foi o da sustentabilidade. O termo discurso aqui utilizado é definido por Fairclough (2001), como sendo a utilização da linguagem como forma de prática social. Ou seja, o discurso é visto como uma das maneiras de os indivíduos agirem, interagirem e representarem o mundo. Dentro dessa perspectiva, o discurso empresarial é composto por todos os aspectos da vida da organização -, os comportamentos de seus membros, as decisões implementadas, os rituais e as mensagens strictu sensu, em texto ou fala. Desse modo, por meio do conceito da sustentabilidade as empresas enfatizam os seus compromissos com uma atuação social e ambiental responsável, lucros e sucesso empresarial, relacionamento com as comunidades localizadas nas áreas de atuação e o desenvolvimento sustentável como uma questão estratégica de longo prazo.

Ambas as empresas possuem o mesmo discurso sobre o conceito e a necessidade do gerenciamento da sustentabilidade empresarial, baseando-se no tripé da sustentabilidade (econômico, social e ambiental). Junto com esse está o discurso de compromisso e de diálogo com os stakeholders. Além disso, grande ênfase é dada à transparência na prestação de contas de suas ações à sociedade, sendo que uma estratégia utilizada para reforçar essa transparência é a verificação independente dos relatórios socio ambiental, prática já adotada por uma das empresas.

O tema responsabilidade social apresenta-se como elemento relevante nas políticas das empresas, e elas fazem questão de marcar o seu posicionamento como empresas socialmente responsáveis.

Com base no modelo de Fombrun et al. (2001), ficou evidente no discurso das empresas que a motivação central para as suas ações de envolvimento com a comunidade é a agregação de valor por meio da minimização dos riscos potenciais relacionados, principalmente, à má aceitação dos plantios extensivos de eucalipto. Ressalta-se, entretanto, que as empresas apresentam projetos que aumentam as suas vantagens competitivas, por meio do programa de fomento florestal e dos projetos voltados para a formação e capacitação de mão-de-obra local especializada em atividades fins das empresas, a exemplo do programa de qualificação profissional para operadores de máquinas de colheita.

Os discursos das empresas evidenciam, ainda, que elas consideram que as responsabilidades corporativas devem ir além da responsabilidade clássica de maximizar os retornos dos acionistas, demonstrando uma visão de que as ações de responsabilidade social são fontes de agregação de valor para elas. Como prova da evidência dessa atitude, ambas empresas são signatárias do Pacto Global (GLOBAL COMPACT), 
movimento capitaneado pela ONU, em que as empresas assumem compromissos globais, incorporando ao cotidiano dos negócios princípios que se baseiam no paradigma do desenvolvimento humano sustentável e que ressaltam a importância das empresas na construção de uma sociedade mais justa e mais equânime.

\section{CONCLUSÕES E RECOMENDAÇÕES}

De acordo com a tipologia do modelo de Quazi e O'brien (2000), as empresas podem ser enquadradas no eixo de responsabilidade ampla, com uma visão moderna de responsabilidade social.

Baseando-se nos dados do discurso e nos resultados das entrevistas, em relação à tipologia de Rochlin e Boguslaw (2001) é possível concluir que as empresas já evoluíram do estágio inicial para o segundo estágio de envolvimento com as comunidades (Experiente). Ressalta-se, entretanto, que já apresentam projetos característicos do estágio mais avançado (Integração), alinhados com as atividades fins e envolvendo diferentes áreas das empresas. Contudo, de acordo com as análises efetuadas, verificou-se que as ações sociais das empresas têm sido realizadas de maneira reativa às diferentes demandas das comunidades ou de instituições externas, sem uma clara definição dos stakeholders prioritários, sem clareza nos objetivos a serem alcançados no envolvimento com as comunidades e, principalmente, no pouco alinhamento com às atividades operacionais das empresas.

A maioria das ações que estão sendo feitas, pouco ou nada, tem a ver com as atividades principais das empresas, não havendo indicadores estruturados para que os impactos alcançados possam ser avaliados. A avaliação dos projetos ainda é vista como uma atividade isolada, realizada geralmente ao seu término com o propósito de controle ou fiscalização.

Considerando a natureza das críticas a que as empresas são submetidas, conclui-se que apenas o fomento florestal e os projetos de geração de emprego e renda estão contribuindo para agregar valor sustentável para as empresas e a sociedade. Os demais projetos não têm viabilizado essa agregação de valor, em razão de sua perspectiva e prática metodológica, que não partem dos problemas e demandas significativos dos grupos envolvidos pelos projetos.

Recomenda-se, então, que as empresas busquem uma mudança nos seus procedimentos de identificação e definição dos seus projetos de envolvimento com as comunidades, passando a definir e explicitar os objetivos, prioridades e forma de atuação, e considerando as suas estratégias de agregação de valor e de sustentabilidade empresarial. Além disso, é necessário um procedimento planejado de avaliação, tanto das metas estabelecidas quanto dos impactos dos projetos, definindo critérios e indicadores e utilizando o processo de avaliação como instrumento para melhorar sua atuação direta sobre o público-alvo e sobre o seu processo de gestão e estratégia de divulgação dos projetos.

Além de atuarem na mesma região, ficou evidenciado na análise realizada que as empresas estudadas compartilham a visão de que as ações de responsabilidade social são fontes de agregação de valor. Identificouse, assim, uma oportunidade para que essas ações sejam potencializadas pelo efeito em escala, tanto do ponto de vista da competitividade quanto do desenvolvimento sustentável, por meio da adoção de um plano de ação conjunto entre as empresas, envolvendo fornecedores e alianças locais. Dessa forma, por meio de parcerias e de alianças estratégicas as empresas podem desenvolver novas atividades, iniciar novos projetos, ampliar os stakeholders a serem atendidos, fortalecer projetos em andamento, ampliar o leque de conhecimentos, captar recursos, economizar recursos humanos e materiais sem prejuízo do trabalho e aumentar a capacidade de intervenção.

\section{REFERÊNCIAS BIBLIOGRÁFICAS}

BARDIN, L. Análise de conteúdo. Lisboa: Edições 70, 1979. 229 p.

BOGDAN, R.; BIKLEN, S. Investigação qualitativa em educação. Porto: Porto Editora, 1994. 336 p.

BORGER, F. G. Responsabilidade social: efeitos da atuação social na dinâmica empresarial. 2001. 254 f. Tese (Doutorado em Administração) Universidade de São Paulo, São Paulo, 2001.

DESLANDES, S. F. A construção do projeto de pesquisa. In: MINAYO, M. C. S. et al. (Org.)

Pesquisa social: teoria, método e criatividade. 2. ed. Petrópolis: Vozes, 1994. p. $31-50$.

R. Árvore, Viçosa-MG, v.30, n.6, p.951-960, 2006 
DUARTE, G. D.; DIAS, J. M. M.

Responsabilidade social: a empresa hoje. Rio de Janeiro: LTC, 1986. 139 p.

\section{INSTITUTO ETHOS DE EMPRESAS E} RESPONSABILIDADE SOCIAL - ETHOS. Perguntas Frequientes. Disponível em: <http://www.ethos.org.br/docs/institucional/ perguntas.html>. Acesso em: 16 set. 2004.

FAIRCLOUGH, N. Discurso e mudança social. Brasília: Universidade de Brasília, 2001.316 p.

FEDERAÇÃO DE ÓRGÃOS PARAASSISTÊNCIA SOCIAL E EDUCACIONAL - FASE. Projetos e ações do Programa Regional Espírito Santo. Disponível em: <http://www.fase.org.br/ regionais.asp?categoria=regional_espirito_santo $>$. Acesso em 03 fev. 2005.

FOMBRUN, C.; GARDBERG, N.; BARNETT, M. L. Opportunity platforms and safety nets: corporate citizenship and reputational risk. Business and Society Review, v. 105, n. 1, p. 85-106, 2001.

\section{GRUPO DE INSTITUTOS, FUNDAÇÕES E} EMPRESAS - GIFE. Investimento Social Privado. Disponível em: < http:// www.gife.org.br/>. Acesso em: 15 out. 2004.

KRIPPENDORFF, K. Content analysis: an introduction to its methodology. Newbury Park: Sage Publications, 1980. 189 p.

LÜDKE, M.; ANDRÉ, M. E. D. Pesquisa em educação: abordagens qualitativas. São Paulo: EPU, 1986. 99 p.

MCWILLIAMS, A.; SIEGEL, D. Corporate social responsibility: A theory of firm perspective.

Academy of Management Review, v. 26, n.1, p. 117-127, 2001.

R. Árvore, Viçosa-MG, v.30, n.6, p.951-960, 2006
MONAGHAN, P.; SABATER, C.; WEISER, J. Business and economic development: the impact of corporate responsibility standards and practices. Disponível em:

$<$ www.accaglobal.com/pdfs/environment/ newsletter/060303_bus_ed.pdf. 2003>. Acesso em: 25 nov. 2003.

MOTA, A. M. et al. Avaliação da dinâmica demográfica e desenvolvimento territorial dos municípios da área de influência do plantio e beneficiamento de eucalipto no Extremo Sul da Bahia e Norte do Espírito Santo: análise e delineamento de ações para a promoção do desenvolvimento sustentável. Salvador: PLANARQ, 2003. 166 p. (Relatório Final).

QUAZI, A. M.; O'BRIEN, D. An empirical test of a cross-national model of corporate social responsibility. Journal of Business Ethics, v. 25, n. 1, p. 33-51, 2000.

RICHARDSON, R. J. et al. Pesquisa social: métodos e técnicas. 3. ed. São Paulo: Atlas, 1999. 287 p.

ROCHLIN, S.; BOGUSLAW, J. Business and community development: aligning corporate performance with community economic development to achieve win-win impacts. Chestnut Hill, MA: The Center for Corporate Citizenship at Boston College, 2001. 50 p.

TEODÓSIO, A. S. S. Construindo planos estratégicos de cidadania empresarial: a experiência de micro-empresários em uma incubadora tecnológica no Brasil. In: CONGRESSO LATINOAMERICANO DE ESTRATÉGIA - DEL PENSAMIENTO A LA ACCIÓN ESTRATÉGICA, 13., 2000, Puebla. Memórias... Puebla: Sociedade Latinoamericana de Estratégia, 2000. p. 83-85. 